\title{
Evaluation of HIV RNA and markers of immune activation as predictors of HIV-associated dementia
}

\author{
J.J. Sevigny, MD; S.M. Albert, PhD; M.P. McDermott, PhD; J.C. McArthur, MBBS, MPH; N. Sacktor, MD; \\ K. Conant, MD; G. Schifitto, MD; O.A. Selnes, PhD; Y. Stern, PhD; D.R. McClernon, BS; D. Palumbo, PhD; \\ K. Kieburtz, MD, MPH; G. Riggs, MD, PhD; B. Cohen, MD; L.G. Epstein, MD; and K. Marder, MD, MPH
}

\begin{abstract}
Objective: To evaluate whether baseline levels of plasma and CSF HIV RNA, tumor necrosis factor alpha $(\mathrm{TNF} \alpha)$, monocyte chemoattractant protein-1 (MCP-1), matrix metalloproteinase-2 (MMP-2), or macrophage colony stimulating factor (M-CSF) are predictors of incident HIV-associated dementia (HIVD) in a cohort with advanced HIV infection. Methods: A total of 203 nondemented subjects with CD4 lymphocyte counts less than $200 / \mu \mathrm{L}$, or $<300 / \mu \mathrm{L}$ but with cognitive impairment, underwent semiannual neurologic, cognitive, functional, and laboratory assessments. HIVD and minor cognitive motor disorder (MCMD) were defined using American Academy of Neurology criteria. The cumulative incidence of HIVD was estimated using Kaplan-Meier curves. Cox proportional hazards regression models were used to examine the associations between biologic variables and time to HIVD, adjusting for age, sex, years of education, duration of HIV infection, type of antiretroviral use, premorbid IQ score, and presence of MCMD. Results: After a median follow-up time of 20.7 months, $74(36 \%)$ subjects reached the HIVD endpoint. The dementia was mild in $70 \%$ of cases. The cumulative incidence of HIVD was $20 \%$ at 1 year and $33 \%$ at 2 years. Highly active antiretroviral therapy (HAART) was used by $73 \%$ of subjects at baseline. A plasma HIV RNA level was undetectable in $23 \%$ of subjects and a CSF HIV RNA level was undetectable in $48 \%$ of subjects. In adjusted analyses, neither plasma nor CSF HIV RNA levels (log 10 ) were associated with time to HIVD; $\log _{10}$ levels of plasma TNF $\alpha(\mathrm{HR} 3.07, p=0.03)$ and CSF MCP-1 (HR = 3.36, $\left.p=0.06\right)$ tended to be associated with time to HIVD. Conclusion: The lack of association between baseline plasma and CSF HIV RNA levels and incident dementia suggests highly active antiretroviral therapy may be affecting CNS viral dynamics, leading to lower HIV RNA levels, and therefore weakening the utility of baseline HIV RNA levels as predictors of HIV-associated dementia.
\end{abstract}

NEUROLOGY 2004;63:2084-2090

Longitudinal studies have shown a $50 \%$ decline in the incidence of HIV-associated dementia (HIVD) over the past decade., ${ }^{1,2}$ This trend mirrors the decline in the incidence of other HIV-associated illnesses, ${ }^{2-4}$ and is largely attributed to the widespread use of highly active antiretroviral therapy (HAART) that began in 1996. The impact of HAART on the incidence of HIVD among those with advanced HIV or those whose immune system fails to reconstitute despite antiretroviral treatment remains less certain. Moreover, there is now evidence that since HAART's introduction, the proportion of incident cases of HIVD occurring among those with CD4 lymphocyte counts greater than 200 cells/ $\mu \mathrm{L}$ is growing. ${ }^{1}$

To a large extent, the difficulty in understanding the epidemiology of HIVD stems from its complex pathogenesis, chronic and insidious course, and the lack of surrogate markers to predict its onset. Stud- ies performed prior to the widespread use of HAART have implicated the role, direct or indirect, of HIV within the CNS. For example, CSF HIV RNA levels were associated with the degree of HIV encephalitis (HIVE), ${ }^{5}$ cognitive impairment, ${ }^{6}$ and severity of dementia, ${ }^{7,8}$ and, in the only longitudinal study published, predicted subsequent cognitive impairment. ${ }^{9}$ While the role of elevated plasma HIV RNA level appears to be less critical, ${ }^{6-9}$ one study found it to be a predictor of HIVD. ${ }^{10} \mathrm{~A}$ possible contribution of various host factors, primarily soluble markers of immune activation elaborated by microglia, resident macrophages and monocytes, and astrocytes, to the pathogenesis of HIVD has also been documented. In particular, elevated CSF levels of monocyte chemoattractant protein-1 (MCP-1), ${ }^{11-13}$ matrix metalloproteinases (MMP), ${ }^{14,15}$ macrophage colony stimulating factor (M-CSF), ${ }^{16}$ and tumor necrosis factor alpha $(\mathrm{TNF} \alpha)^{17}$ have been reported in those with HIVD. To

From Columbia University and The Taub Institute (Drs. Sevigny, Albert, Stern, and Marder), New York, NY; University of Rochester (Drs. McDermott, Schifitto, Palumbo, Kieburtz, and Riggs), Rochester, NY; Johns Hopkins University School of Medicine (J.C. McArthur, and Drs. Sacktor, Conant, and Selnes), Baltimore, MD; Departments of Neurology (Dr. Cohen) and Pediatrics (Dr. Epstein), Feinberg School of Medicine at Northwestern University, Chicago, IL; and GlaxoSmithKline, Inc. (D.R. McClernon), Research Triangle Park, NC.

Supported by NIH grants NS049465, NS36519, NS44807, NS26643, RR00522, RR00044, RR00645.

Received January 22, 2004. Accepted in final form August 12, 2004.

Address correspondence and reprint requests to Dr. Karen Marder, Columbia University College of Physicians and Surgeons, Department of Neurology, 622 W168th Street, New York, NY 10032; e-mail: kmarder@sergievsky.cpmc.columbia.edu

2084 Copyright @ 2004 by AAN Enterprises, Inc. 
date, no study has examined whether they are predictors of HIVD.

In a study performed prior to the widespread use of HAART in an advanced HIV cohort using similar methods, we reported the cumulative annual incidence of HIVD to be approximately $25 \%$ and described several predictors associated with this outcome. ${ }^{18}$ In the study, we sought to evaluate whether CSF or plasma levels of HIV RNA or markers of immune activation, including $\mathrm{TNF} \alpha$, MCP-1, M-CSF, and MMP-2, are predictors of incident HIVD among those with advanced HIV.

Materials and methods. The North-East AIDS Dementia (NEAD) consortium was formed in 1998 to evaluate factors associated with HIVD or mild cognitive/motor disorder (MCMD) in individuals with advanced HIV infection. A total of 395 subjects were recruited through targeted advertising or from infectious disease clinics at four sites: Columbia University, New York, NY; Johns Hopkins University, Baltimore, MD; University of Rochester, NY; and, beginning in 1999, Northwestern University, Chicago, IL. To be eligible, subjects had to meet the following inclusion criteria: HIV seropositive, capable of providing informed consent, ambulatory at initial visit, and $\mathrm{CD} 4^{+}$lymphocyte cell count either below 200 cells $/ \mu \mathrm{L}$ or below 300 cells/ $\mu \mathrm{L}$ but with cognitive impairment demonstrated by neuropsychological testing (see below). Subjects with a current or past CNS infection, schizophrenia, severe affective disorder, or other chronic neurologic disorder were excluded from the cohort. Substance abusers, remote or active, were not excluded but were not examined if judged by the examiner to be intoxicated.

Procedures. Every 6 months subjects underwent a standardized neurologic examination; completed a battery of neuropsychological, functional, and psychiatric assessments; and had blood drawn for laboratory studies. Subjects were asked to undergo a lumbar puncture at the initial visit and annually thereafter.

Independent variables. Demographic. At the initial visit age, sex, race, and years of education were collected.

HIV-related history. At the initial visit and, where applicable, each follow-up we ascertained years since HIV diagnosis, type of antiretroviral (ARV) use, and occurrence of any HIV-related illnesses. The type of ARV use was classified as none, 1 to $2 \mathrm{ARVs}$, $\geq 3$ ARVs (HAART). We further subdivided HAART regimens according to the presence of a protease inhibitor (PI) or $>2$ CNSpenetrant ARVs. The following ARVs were considered to have CNS penetrance: zidovudine, stavudine, abacavir, indinavir, efavirenz, and nevirapine. We used a cutoff of two CNS-penetrant ARVs to define CNS penetrant HAART based on prior studies suggesting that HAART regimens containing two or more CNSpenetrant ARVs may be associated with improved neurologic outcomes. ${ }^{19,20}$

Neurologic examination. A macro-neurologic examination created for the AIDS Clinical Trials Group (ACTG) and the motor subscale (part III) of the Unified PD Rating Scale (UPDRS) ${ }^{21}$ were utilized to assess extrapyramidal signs associated with HIVD. The total score for each examination was calculated at each visit and dichotomized using the same cutoff points as in our prior studies..$^{18}$

Neuropsychological testing. The neuropsychological battery was designed to quantify the cognitive impairment associated with HIVD and MCMD and utilized tests recommended by the National Institutes of Mental Health ${ }^{22}$ and ACTG. The core battery is comprised of eight tests covering six cognitive domains: verbal memory: Rey Auditory Verbal Learning Test ${ }^{23}$; visual memory: Rey-Osterrieth Complex Figure Delayed Recall Test ${ }^{23}$; construction: Rey-Osterrieth Complex Figure Copy; psychomotor: Digit Symbol test ${ }^{24}$; motor speed: Grooved Pegboard ${ }^{25}$ and timed gait; frontal system: Verbal Fluency ${ }^{26}$ and Odd-Man-Out test. ${ }^{27,28}$ In addition, general intellectual function was estimated with the National Adult Reading Test (NART) ${ }^{29,30}$ and reaction time with the California Computerized Assessment Package (CALCAP). ${ }^{31}$

Performance on each test was referenced to age and education appropriate norms where available. ${ }^{32,33}$ Neuropsychological test scores were dichotomized at $1 \mathrm{SD}$ below the mean, except for Timed Gait for which a cutoff of 1.5 SDs below the mean was used.
Test score values at or below the corresponding cutoffs were considered abnormal. Cognitive impairment was defined as performing at least $1 \mathrm{SD}$ below the mean on two separate tests or $2 \mathrm{SDs}$ below the mean on one test. If Timed Gait was the only test for which a score was 2 SDs below the mean, then criteria for cognitive impairment were not met.

Functional outcomes. Basic activities of daily living were assessed with the Katz Activities of Daily Living Scale ${ }^{34}$ high-level function with the Instrumental Activities of Daily Living (IADL) scales of Lawton and Brody, ${ }^{35}$ and daily activity with the role functioning items from the Medical Outcomes Study (MOS) ${ }^{36}$ Karnofsky Performance Scale ${ }^{37}$ scores and the MOS Physical Function subscale, ${ }^{36}$ both functional outcome scales that stress physical strength and stamina, were also completed, but neither was used in the definition of HIVD or MCMD. All scores were dichotomized using the same cutoff points as in our prior studies..$^{18}$

Psychiatric assessment. Mood was assessed with the selfadministered Beck depression scale and treated as a continuous variable in the analyses. ${ }^{38,39}$

Laboratory assessment. Baseline CD4 lymphocyte count, hematocrit, and levels of HIV RNA, MCP-1, TNF $\alpha, \mathrm{M}-\mathrm{CSF}$, and MMP-2 in CSF and plasma were obtained. HIV RNA levels were determined using the NucliSens QT assay (bioMerieux, Inc., Durham, NC; lod 80 copies $/ \mathrm{mL}$ ). Levels of the immune activation markers TNF $\alpha$, MCP-1, M-CSF, and MMP-2 were determined by using Quantikine ELISA kits (R \& D Systems, Minneapolis, MN; lod $31.2 \mathrm{pg} / \mathrm{mL}$ ). Values were log-transformed in base 10, except CD4 lymphocyte count for which base e was used, and treated as continuous variables in the analyses. We also created a separate dependent variable for a stratified group of only those with a baseline CD4 lymphocyte count less than 200 cells/ $\mu \mathrm{L}$ (transformed into log base e). Finally, dependent variables representing the log transformed CSF to plasma ratios for both HIV RNA and MCP-1 were created.

Diagnosis of HIV-D and MCMD. Subjects were categorized as normal, MCMD, or HIVD using the AAN criteria. ${ }^{40}$ Severity of dementia was assessed using the modified Memorial Sloan Kettering (MSK) classification. ${ }^{41}$ Inter-rater reliability among sites was good. ${ }^{42}$

Data analyses. The primary outcome for this study was time to HIVD. Analyses were performed only on those who were not demented (i.e., categorized as normal or MCMD) at baseline and had at least one semiannual follow-up visit. For those who did not reach the outcome of HIVD, follow-up time was censored at the last available visit. Baseline variables were compared between those who reached the HIVD endpoint and those who remained nondemented using $t$-tests for continuous variables and $\chi^{2}$ tests for categorical variables. To explore how the type of ARV treatment may have influenced the values of the baseline biologic variables, comparisons were made between those on no ARVs and those on HAART. Kaplan-Meier curves were constructed to estimate the cumulative incidence of HIVD.

Associations between the independent variables and time to HIVD were examined using Cox proportional hazards regression models. First, univariate analyses were performed, and based on these results multivariate models were created. Each multivariate model contained the following eight variables considered relevant to the prediction of HIVD: age, sex, years of education, NART score, duration of HIV infection, type of ARV use (none, one to two ARVs, or HAART), and baseline neurologic status (MCMD vs normal). To this base set of predictors, we added a plasma or CSF marker, or ratio thereof, as an independent variable, creating separate regression models consisting of eight independent variables each. Finally, we tested for interactions between HIV RNA levels (CSF, plasma, and the CSF/plasma ratio) and the type of ARV use (HAART vs none) by adding the appropriate interaction term to each multivariate model. All of the Cox proportional hazards regression models included site of enrollment as a stratification factor.

Results. A total of 254 subjects (64\%) were categorized as nondemented at the baseline visit, of whom 51 had no follow-up, leaving 203 subjects for inclusion in the time to HIVD analyses. Of the 203 subjects, $48 \%$ were classified as normal and 52\% were classified as MCMD at their baseline visit. Seventy-four subjects $(36 \%)$ reached the HIVD 
Table 1 Summary statistics for baseline demographic and biological variables measured at initial visit

\begin{tabular}{|c|c|c|c|c|}
\hline & All, $\mathrm{n}=203$ & Non-demented, $\mathrm{n}=129$ & Incident dementia, $\mathrm{n}=74$ & $p$ \\
\hline Age, y & $42.0(7.2)$ & $41.6(7.4)$ & $42.5(6.7)$ & 0.39 \\
\hline Male, $\%$ & 73.4 & 79.1 & 63.5 & 0.02 \\
\hline \multicolumn{5}{|l|}{ Ethnicity, \% } \\
\hline White & 26.1 & 30.2 & 18.9 & \multirow{4}{*}{0.36} \\
\hline Black & 64.0 & 60.5 & 70.3 & \\
\hline Hispanic & 8.9 & 8.5 & 9.5 & \\
\hline Other & 1.0 & 0.8 & 1.4 & \\
\hline Years of education & $12.5(2.5)$ & $12.8(2.5)$ & $12.0(2.3)$ & 0.03 \\
\hline NART & $98.1(11.4)$ & $99.9(11.7)$ & $94.9(10.3)$ & 0.003 \\
\hline \multicolumn{5}{|l|}{ ARV use, \% } \\
\hline None & 21.4 & 20.2 & 23.6 & \multirow{3}{*}{0.33} \\
\hline $1-2$ & 6.0 & 7.8 & 2.8 & \\
\hline HAART & 72.6 & 72.1 & 73.6 & \\
\hline Years since HIV diagnosis & $7.2(4.3)$ & $7.1(4.3)$ & $7.3(4.4)$ & 0.68 \\
\hline HIV-related diagnosis, $\%$ & 62.1 & 56.6 & 71.6 & 0.03 \\
\hline \multicolumn{5}{|c|}{ CD4 lymphocyte count, $\mathrm{n}=202$} \\
\hline Median & $127.5(69,194)$ & $130.0(72,191)$ & $118.0(64,97)$ & \multirow{2}{*}{0.69} \\
\hline Mean* & $4.6(0.9)$ & $4.6(0.9)$ & $4.6(0.9)$ & \\
\hline \multicolumn{5}{|c|}{ Plasma HIV RNA level, $\%, \mathrm{n}=178$} \\
\hline Undetectable & 22.5 & 23.6 & 20.6 & \multirow{4}{*}{0.67} \\
\hline $80-10,000$ & 26.4 & 26.4 & 26.5 & \\
\hline $10,000-100,000$ & 32.0 & 33.6 & 29.4 & \\
\hline$>100,000$ & 19.1 & 16.4 & 23.5 & \\
\hline \multicolumn{5}{|l|}{ Plasma HIV RNA level } \\
\hline Median & $11,500(270,66,000)$ & $9,800(93,51,000)$ & $16,000(775,965,000)$ & \\
\hline Mean $\dagger$ & $3.8(1.3)$ & $3.7(1.3)$ & $3.9(1.3)$ & 0.23 \\
\hline \multicolumn{5}{|c|}{ CSF HIV RNA level, $\%, \mathrm{n}=126$} \\
\hline Undetectable & 47.6 & 50.0 & 43.5 & \multirow{3}{*}{0.60} \\
\hline $80-1,000$ & 27.0 & 27.5 & 26.1 & \\
\hline$>1,000$ & 25.4 & 22.5 & 30.4 & \\
\hline \multicolumn{5}{|l|}{ CSF HIV RNA level } \\
\hline Median & $90(80,1,100)$ & $83(80,750)$ & $240(80,1,900)$ & \multirow{2}{*}{0.16} \\
\hline Mean $\dagger$ & $2.5(0.8)$ & $2.5(0.8)$ & $2.7(0.9)$ & \\
\hline \multicolumn{5}{|c|}{ Plasma MCP-1 level, n = 157} \\
\hline Median & $0.27(0.18,0.40)$ & $0.30(0.19,0.41)$ & $0.23(0.17,0.37)$ & \\
\hline Mean $\dagger$ & $-0.6(0.4)$ & $-0.6(0.3)$ & $-0.6(0.5)$ & 0.49 \\
\hline \multicolumn{5}{|l|}{ CSF MCP-1, $\mathrm{n}=110$} \\
\hline Median & $0.47(0.31,0.73)$ & $0.47(0.30,0.72)$ & $0.52(0.31,0.74)$ & \\
\hline Mean $\dagger$ & $-0.3(0.3)$ & $-0.4(0.3)$ & $-0.3(0.3)$ & 0.30 \\
\hline \multicolumn{5}{|l|}{ Plasma TNF- $\alpha, \mathrm{n}=157$} \\
\hline Median & $5.62(3.71,8.05)$ & $5.53(3.58,8.05)$ & $5.70(4.08,8.16)$ & \\
\hline Mean $\dagger$ & $0.7(0.3)$ & $0.7(0.3)$ & $0.8(0.3)$ & 0.26 \\
\hline \multicolumn{5}{|l|}{ CSF TNF- $\alpha, \mathrm{n}=93$} \\
\hline Median & $1.45(0.74,4.43)$ & $1.86(0.72,4.81)$ & $1.29(0.74,3.26)$ & \\
\hline Mean $\dagger$ & $0.2(0.6)$ & $0.3(0.7)$ & $0.2(0.5)$ & 0.67 \\
\hline \multicolumn{5}{|l|}{ Plasma M-CSF, n = 157} \\
\hline Median & $2.03(1.23,4.21)$ & $2.00(1.10,4.22)$ & $2.25(1.32,4.21)$ & \\
\hline Mean $\dagger$ & $0.3(0.4)$ & $0.3(0.4)$ & $0.3(0.4)$ & 0.99 \\
\hline CSF M-CSF, $\mathrm{n}=108$ & & & & \\
\hline Median & $0.79(0.47,1.29)$ & $0.78(0.42,1.27)$ & $0.84(0.54,1.34)$ & \\
\hline Mean $\dagger$ & $-0.1(0.4)$ & $-0.2(0.4)$ & $-0.1(0.4)$ & 0.71 \\
\hline Plasma MMP-2, n = 155 & & & & \\
\hline Median & $220.9(167.5,267.3)$ & $226.4(171.1,272.2)$ & $195.8(165.8,247.9)$ & \\
\hline Mean $\dagger$ & $2.3(0.2)$ & $2.3(0.2)$ & $2.3(0.1)$ & 0.40 \\
\hline CSF MMP-2, $\mathrm{n}=110$ & & & & \\
\hline Median & $60.9(44.0,90.8)$ & $61.0(42.3,91.5)$ & $60.7(44.2,87.6)$ & \\
\hline Mean $\dagger$ & $1.8(0.3)$ & $1.8(0.3)$ & $1.8(0.3)$ & 0.78 \\
\hline
\end{tabular}

Mean values accompanied by (SD). Median values accompanied by (interquartile range).

* Log transformed (base e).

$\dagger$ Log transformed (base 10).

NART $=$ National Adult Reading Test; ARV = antiretroviral; HAART = highly active antiretroviral therapy. 


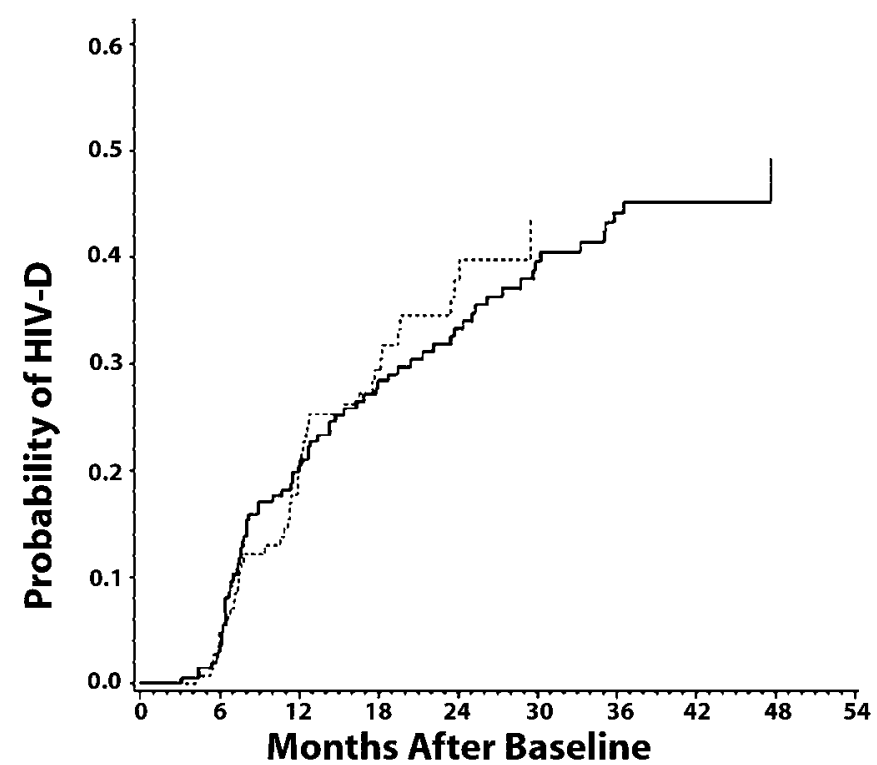

Figure. Kaplan-Meier curves of the cumulative incidence of HIV-associated dementia in the North-East AIDS Dementia (NEAD) cohort compared with the Dana cohort (dashed line, from Dana; solid line, from NEAD).

endpoint. Median follow-up time was 20.7 months (3.2 to 53.7 months). Baseline demographic, biologic, and neurologic characteristics between those who reached the HIVD endpoint and those who did not were similar except for sex, years of education, NART score, and history of HIVrelated illness (table 1 ).

The most commonly used antiretroviral medications at baseline were as follows: lamivudine: $54.3 \%$, zidovudine: $37.3 \%$ stavudine: $33.8 \%$, didanosine: $20.4 \%$, nelfinavir: $19.4 \%$, indinavir: $19.4 \%$, efavirenz: $14.9 \%$, saquinavir: $13.4 \%$, ritonavir: $12.4 \%$, abacavir: $12.0 \%$, and nevirapine: $11.0 \%$. HAART was being used by $73 \%$ of subjects at baseline, and of those $56 \%$ remained on it throughout the study. Of the $27 \%$ of subjects not using HAART at baseline, $71 \%$ reported its use on least one follow-up visit. Overall, $90 \%$ of the subjects used HAART at least once during the study. In crossclassification analysis based on HAART use at baseline (yes, no) and HAART use ever on follow-up (yes, no), risk of incident dementia did not differ among the four groups.

The estimated cumulative incidence of HIVD was $20 \%$ at 1 year and $33 \%$ at 2 years. (figure) The severity of dementia was mild in $70 \%$ of the cases.

In univariate analyses (table 2), associations were found between time to HIVD and CSF MCP-1 (HR 3.14; $p=0.05$ ) and plasma $\mathrm{TNF} \alpha$ (HR 2.54; $p=0.04$ ). No associations with time to HIVD were found for plasma CD4+ lymphocytes (even when stratified to include only those with less than 200 cells/ $\mu \mathrm{L}$ ), HIV RNA, MCP-1, MMP-2, and M-CSF; CSF HIV RNA, TNF $\alpha$, MMP-2, and M-CSF; or CSF: plasma ratios of HIV RNA and MCP-1.

Other variables that were associated with incident HIVD in univariate analyses included female sex, fewer years of education, lower NART score, lower hematocrit, presence of MCMD, Beck depression score > 15, Karnofsky performance score $<90$, macroneurological score $>8$, Motor UPDRS score $>4$, Instrumental ADL score $<24$, and Physical Function score $<23$ (table 3). Type of ARV used at baseline (none, one to two ARVs, HAART) was not asso-
Table 2 Univariate analyses of selected demographic and biological variables

\begin{tabular}{|c|c|c|c|}
\hline & $\mathrm{HR}$ & $95 \% \mathrm{CI}$ & $p$ \\
\hline Age, y & 1.01 & $0.98-1.04$ & 0.72 \\
\hline Female sex & 1.59 & $0.98-2.57$ & 0.06 \\
\hline Race, non-white & 0.98 & $0.50-1.92$ & 0.96 \\
\hline Years of education & 0.87 & $0.77-0.97$ & 0.01 \\
\hline Years since diagnosed with HIV & 1.04 & $0.98-1.10$ & 0.19 \\
\hline History of HIV-related diagnoses & 1.46 & $0.91-2.33$ & 0.12 \\
\hline \multicolumn{4}{|l|}{ ARV use } \\
\hline None & 1.00 & & \\
\hline $1-2$ & 0.40 & $0.09-1.74$ & 0.29 \\
\hline HAART & 1.20 & $0.68-2.09$ & \\
\hline Hematocrit & 0.94 & $0.90-0.98$ & 0.005 \\
\hline CD4 lymphocyte count* $(\mathrm{n}=202)$ & 1.00 & $0.78-1.29$ & 0.98 \\
\hline Plasma HIV RNA* ( $\mathrm{n}=178)$ & 1.14 & $0.94-1.38$ & 0.19 \\
\hline CSF HIV RNA* $(\mathrm{n}=126)$ & 1.17 & $0.86-1.59$ & 0.33 \\
\hline Plasma MCP-1* $(\mathrm{n}=157)$ & 1.32 & $0.60-2.92$ & 0.49 \\
\hline CSF MCP-1* $(\mathrm{n}=110)$ & 3.14 & $1.00-9.87$ & 0.05 \\
\hline Plasma M-CSF* $(\mathrm{n}=157)$ & 0.87 & $0.45-1.72$ & 0.70 \\
\hline CSF M-CSF* $(n=108)$ & 0.73 & $0.26-2.10$ & 0.56 \\
\hline Plasma MMP-2* $(\mathrm{n}=155)$ & 0.37 & $0.08-1.72$ & 0.20 \\
\hline CSF MMP-2* $(n=110)$ & 0.82 & $0.36-1.85$ & 0.63 \\
\hline Plasma TNF- $\alpha^{*}(\mathrm{n}=157)$ & 2.54 & $1.06-6.06$ & 0.04 \\
\hline CSF TNF- $\alpha *(n=93)$ & 0.89 & $0.47-1.67$ & 0.71 \\
\hline Plasma/CSF HIV RNA (n = 126) & 0.96 & $0.76-1.21$ & 0.73 \\
\hline Plasma/CSF MCP-1 (n = 110) & 1.70 & $0.81-3.57$ & 0.16 \\
\hline
\end{tabular}

* Log transformed values.

$\mathrm{HR}=$ hazard ratio; ARV $=$ antiretroviral; HAART $=$ highly active antiretroviral therapy.

ciated with time to HIVD, even when subdividing HAART by whether it contained a PI or $\geq 2$ CNS-penetrant ARVs.

In the multivariate analyses (table 4), only plasma $\mathrm{TNF} \alpha$ was significantly associated with time to HIVD (HR 3.07; $p=0.03$ ), although CSF MCP-1 demonstrated borderline significance ( $\mathrm{HR} 3.36 ; p=0.06$ ). No significant interactions were found between either CSF or plasma HIV RNA, or their ratio, and type of ARV use.

In comparing biologic variables among groups based on type of ARV use (none vs HAART), those using HAART had a higher CD4+ lymphocyte count (4.7 [0.8] vs 4.4 [0.9]; $p=$ 0.07), lower plasma HIV RNA (3.6 [1.3] vs 4.3 [1.2]; $p<0.001)$, and lower CSF HIV RNA (2.5 [0.8] vs 2.8 [1.0]; $p=0.06$ ) (values log-transformed).

Discussion. In longitudinal follow-up of the NEAD cohort, neither CSF nor plasma levels of HIV RNA were associated with time to HIVD but levels of the markers of immune activation CSF MCP-1 and plasma $\mathrm{TNF} \alpha$ tended to be associated with this outcome.

In prior studies, elevated baseline levels of $\mathrm{CSF}^{9}$ and plasma ${ }^{10} \mathrm{HIV}$ RNA were predictive of neurologic 
Table 3 Univariate analyses of selected neurologic, neuropsychological, psychiatric, and physical function variables

\begin{tabular}{lccc}
\hline & HR & $95 \%$ CI & $p$ \\
\hline Beck score & 1.04 & $1.02-1.06$ & $<0.001$ \\
Beck score $>$ 15 & 2.75 & $1.71-4.44$ & $<0.0001$ \\
Timed gait* & 1.24 & $0.74-2.06$ & 0.41 \\
Verbal fluency $\dagger$ & 0.97 & $0.44-2.15$ & 0.94 \\
Grooved Pegboard $\dagger$ & 1.13 & $0.70-1.82$ & 0.62 \\
Mean Reaction Time Choice $\dagger$ & 1.05 & $0.58-1.89$ & 0.87 \\
Mean Reaction Time Sequential $\dagger$ & 0.77 & $0.41-1.44$ & 0.41 \\
Trail Making (B) $\dagger$ & 1.56 & $0.35-6.93$ & 0.56 \\
Odd Man Out $\dagger$ & 0.95 & $0.49-1.87$ & 0.88 \\
Rey AVM Total Score & 0.98 & $0.60-1.59$ & 0.93 \\
Rey Complex Figure, Copy $\dagger$ & 1.26 & $0.78-2.02$ & 0.35 \\
Rey Complex Figure, Recall $\dagger$ & 0.97 & $0.58-1.61$ & 0.89 \\
Digit Symbol $\dagger$ & 1.03 & $0.55-1.93$ & 0.92 \\
NART score & 0.97 & $0.95-1.00$ & 0.04 \\
MCMD & 2.65 & $1.57-4.47$ & $<0.001$ \\
Karnofsky Performance Score & & & \\
$\quad$ 90-100 & 1.00 & & \\
80-89 & 2.50 & $1.40-4.47$ & $<0.001$ \\
$\quad<$ 80 & 3.81 & $1.94-7.50$ & \\
MacroNeurological Score $>8$ & 2.27 & $1.38-3.73$ & 0.001 \\
Motor UPDRS $>$ 4 & 2.75 & $1.69-4.49$ & $<0.001$ \\
Instrumental ADL $<24$ & 2.01 & $1.23-3.28$ & 0.005 \\
Physical Function Score $<23$ & 1.85 & $1.15-2.99$ & 0.01 \\
Self-Maintenance ADL Score $<18$ & 2.11 & $0.51-8.70$ & 0.30 \\
\hline & & & \\
\hline
\end{tabular}

* 1.5 SDs below the norm.

$\dagger 1.0$ SD below the norm.

$\mathrm{HR}=$ hazard ratio; NART $=$ National Adult Reading Test; MCMD = mild cognitive/motor disorder; UPDRS $=$ Unified Parkinson Disease Rating Scale; ADL = activities of daily living.

deterioration. Important differences among the cohorts, the methods, and the statistical techniques likely contribute to the discordant results. For example, the NEAD cohort has a more advanced HIV infection (based on CD4 lymphocyte count) and appears to be older, less educated, and to contain a greater percentage of non-whites, women, and IV drug users than the other cohorts. Each has been shown to be a risk factor for developing HIVD, ${ }^{10,18,43}$ and in our analyses we adjusted for many of these and other pertinent covariates. Furthermore, the outcome measure was different in each study: we utilized the AAN algorithm for HIVD while the other studies used either less stringent probable HIVD criteria, ${ }^{10}$ a predecessor of the AAN criteria, or changes in neuropsychological performance, ${ }^{9}$ which is but one component of the AAN criteria.

Another distinguishing feature of our cohort is its prevalent (73\%) use of HAART at baseline. HAART substantially reduces plasma and CSF HIV RNA levels ${ }^{20,44-46}$ and has proven to be more efficacious than previous regimens. ${ }^{47-49}$ Indeed, HAART appears to have influenced viral levels in our cohort. Users at
Table 4 Contribution of biological variables to selected model* for time to dementia

\begin{tabular}{|c|c|c|c|}
\hline & $\mathrm{HR}$ & $95 \% \mathrm{CI}$ & $p$ \\
\hline Plasma HIV RNA & 1.14 & $0.91-1.44$ & 0.26 \\
\hline \multicolumn{4}{|l|}{ Plasma HIV RNA } \\
\hline No ART & 1.21 & $0.66-2.20$ & \multirow{2}{*}{$0.86 \dagger$} \\
\hline HAART & 1.14 & $0.88-1.46$ & \\
\hline CSF HIV RNA & 1.14 & $0.81-1.61$ & 0.45 \\
\hline \multicolumn{4}{|l|}{ CSF HIV RNA } \\
\hline No ART & 1.54 & $0.74-3.18$ & \multirow{2}{*}{$0.38 \dagger$} \\
\hline HAART & 1.05 & $0.69-1.59$ & \\
\hline CSF/plasma HIV RNA & 0.88 & $0.67-1.16$ & 0.35 \\
\hline \multicolumn{4}{|l|}{ CSF/plasma HIV RNA } \\
\hline No ART & 1.04 & $0.48-2.27$ & \multirow{2}{*}{$0.57 \dagger$} \\
\hline HAART & 0.82 & $0.61-1.11$ & \\
\hline Plasma MCP-1 & 1.47 & $0.65-3.34$ & 0.36 \\
\hline CSF MCP-1 & 3.36 & $0.94-12.04$ & 0.06 \\
\hline CSF/plasma MCP-1 & 1.13 & $0.54-2.37$ & 0.75 \\
\hline \multicolumn{4}{|l|}{ CSF/plasma MCP-1 } \\
\hline No ART & 0.65 & $0.07-5.87$ & \multirow{2}{*}{$0.63 \dagger$} \\
\hline HAART & 1.13 & $0.53-2.38$ & \\
\hline Plasma M-CSF & 1.04 & $0.47-2.29$ & 0.92 \\
\hline CSF M-CSF & 0.40 & $0.11-1.45$ & 0.16 \\
\hline Plasma MMP-2 & 0.31 & $0.05-1.96$ & 0.21 \\
\hline CSF MMP-2 & 0.62 & $0.26-1.49$ & 0.28 \\
\hline Plasma TNF- $\alpha$ & 3.07 & $1.11-8.49$ & 0.03 \\
\hline CSF TNF- $\alpha$ & 0.73 & $0.35-1.54$ & 0.41 \\
\hline
\end{tabular}

All biological variables entered separately into model as log transformed values.

* Adjusted for age, sex, years of education, duration of HIV infection, type of ARV use, National Adult Reading Test (NART) score, and presence of mild cognitive/motor disorder (MCMD). $\dagger p$ Value for interaction between biological variable and type of ARV use.

$\mathrm{HR}=$ hazard ratio; ART $=$ antiretroviral therapy; HAART $=$ highly active antiretroviral therapy.

their initial visit had lower baseline plasma and CSF viral levels than those on no ARVs, and the cohort's median baseline CSF viral level more closely approximates the substantially reduced post-HAART treatment levels reported from studies assessing HAART's efficacy. ${ }^{20,44,46}$ Therefore, it appears that this cohort had relatively suppressed baseline HIV RNA levels, thereby abrogating the power of baseline HIV RNA levels to predict neurologic outcomes.

Surprisingly, the type of ARV treatment (none, one to two ARVs, HAART, PI-containing HAART, or CNS-penetrant HAART) used at the baseline visit was not a predictor of HIVD. We did not find a significant interaction between HAART use (none vs HAART) and any of the biologic variables, including HIV RNA, in the multivariate models. Caution, however, must be exercised in interpreting these results. These analyses do not take into account issues of treatment selection effects, viral resistance, medica- 
tion non-adherence, or changes in ARVs that may have occurred between the baseline and follow-up visits. Furthermore, reports from other studies suggest that certain types of ARVs, such as those with good CNS penetrance, ${ }^{19}$ may lead to improved neurologic outcomes. Accounting and controlling for these factors would be critical in attempting to determine the effects of specific treatment regimens on the risk for incident dementia. Our study was not designed to answer this question. Instead, this question is best addressed in a randomized clinical trial.

The rationale for evaluating markers of immune activation is that their production would appear to be upregulated in those with dementia, suggesting their culpability in the pathogenesis of HIVD. Of the four markers of immune activation analyzed in plasma and CSF, only plasma $\mathrm{TNF}_{\alpha}$ and $\mathrm{CSF}$ MCP-1 tended to be associated with incident HIVD. Our analyses adjusted for several covariates, although not for multiple comparisons.

TNF- $\alpha$ is a proinflammatory cytokine produced by a variety of cells both systemically and within the CNS. Considered a marker of disease activity, elevated plasma levels have been associated with progression to $\operatorname{AIDS}^{50}$ and with virologic and immunologic treatment failure. ${ }^{51}$ Based on this hypothesis, one could speculate that elevated plasma $\mathrm{TNF} \alpha$ may signify further immune dysregulation or even an incipient rise in HIV RNA levels, and therefore a greater likelihood of neurologic deterioration. Further analyses on follow-up data should help elucidate the relationships among plasma $\mathrm{TNF} \alpha$, HIV RNA levels, and HIVD.

MCP-1, another proinflammatory cytokine, is produced by activated astrocytes, microglia, and CNS macrophages and has a powerful influence on monocyte and macrophage activation and their trafficking between the periphery and the CNS. In a simian model, the CSF:plasma MCP-1 ratio was predictive of SIV encephalitis, ${ }^{52}$ while in human studies, CSF levels of MCP-1 have been associated with HIV encephalitis $^{12}$ and HIVD. ${ }^{11,13}$ How MCP-1 relates to the pathogenesis of HIVD remains speculative. But in light of its poor ${ }^{53}$ and even inverse ${ }^{54}$ association with CSF HIV RNA levels among HAART users, it may be more than just recruitment of virus (via trafficking monocytes/macrophages) into the CNS. Other possible mechanisms might include direct toxic effects on components of the CNS, further upregulation of the present CNS monocyte population, or recruitment of peripheral monocytes-and potentially more toxic ones ${ }^{55}$-into the CNS. ${ }^{56}$

The CD4 lymphocyte count, even when stratified to include only those with less than 200 cells/ $\mu \mathrm{L}$, was not associated with the outcome of HIVD. Studies performed prior to the widespread use of HAART have been inconsistent in finding an association. In one study no association was found, ${ }^{57}$ in another study a weak association was found only among those with a CD4 lymphocyte count less than 200 cells $/ \mu \mathrm{L},{ }^{10}$ and in a third study a significant associa- tion was found in univariate analysis but not in multivariate analysis. ${ }^{58}$ Although our results suggest no association in those with CD4 lymphocyte count less than 300 cells $/ \mu \mathrm{L}$, the study was not designed to address this question and is limited by a narrow range of $\mathrm{CD} 4$ lymphocyte counts.

The 20\% estimated annual cumulative incidence of HIVD in this cohort is statistically similar to the $25 \%$ annual incidence we found in a previous study (see the figure). ${ }^{18}$ These two studies are similar with respect to source population, entry criteria, and study methodology. One important difference, however, is that subjects in the Dana cohort were not exposed to HAART, which, along with its superior virologic control, is associated with a decline in HIVassociated morbidity and mortality, ${ }^{2-4}$ a delay in the onset of cognitive impairment among those with AIDS, ${ }^{59}$ and improvements in neuropsychological test performance in those with HIV-associated cognitive impairment. ${ }^{60-63}$ If HAART is associated with superior virologic control and clinical outcomes, then why were the incidence rates between the two cohorts similar? HIV RNA levels were not measured in the Dana cohort, but if one assumes lower viral levels in the NEAD cohort given HAART use, then the notion that the neuropathogenesis of HIVD is driven by productive HIV RNA infection needs to be challenged. Instead, it may be that once the immune system (microglia, monocytes, and macrophages) is primed by HIV infection, sustained immune failure, independent of viral levels and ARV use, enables the dysregulated production of substances, for example MCP-1, TNF $\alpha$, and stromal derived growth factor (SDF-1), ${ }^{64}$ toxic to the CNS. In this model, as long as there is continued immune failure, the risk of developing dementia remains.

\section{Acknowledgment}

Additional research personnel include Ronda Friedman, B. Clouse, RN, and Paula Leber, BA (Columbia University); Deneen Esposito, BA, Jason Creighton, BA, David Burgess, BA, and A. King (Johns Hopkins University); Connie Orme, BA, Larry Preston, BPS, and Kim Cruttenden, BS (University of Rochester).

\section{References}

1. Sacktor N, Lyles RH, Skolasky R, et al. HIV-associated neurologic disease incidence changes: Multicenter AIDS Cohort Study, 1990-1998. Neurology 2001;56:257-260.

2. Moore RD, Chaisson RE. Natural history of HIV infection in the era of combination antiretroviral therapy. Aids 1999;13:1933-1942.

3. Detels R, Munoz A, McFarlane G, et al. Effectiveness of potent antiretroviral therapy on time to AIDS and death in men with known HIV infection duration. JAMA 1998;280:1497-1503.

4. Hogg RS, Heath KV, Yip B, et al. Improved survival among HIVinfected individuals following initiation of antiretroviral therapy. JAMA 1998;279:450-454.

5. Cinque P, Vago L, Ceresa D, et al. Cerebrospinal fluid HIV-1 RNA levels: correlation with HIV encephalitis. AIDS 1998;12:389-394.

6. Ellis RJ, Hsia K, Spector SA, et al. Cerebrospinal fluid human immunodeficiency virus type 1 RNA levels are elevated in neurocognitively impaired individuals with acquired immunodeficiency syndrome. HIV Neurobehavioral Research Center Group. Ann Neurol 1997;42:679-688.

7. Brew BJ, Pemberton L, Cunningham P, Law MG. Levels of human immunodeficiency virus type 1 RNA in cerebrospinal fluid correlate with AIDS dementia stage. J Infect Dis 1997;175:963-966.

8. McArthur JC, McClernon DR, Cronin MF, et al. Relationship between human immunodeficiency virus-associated dementia and viral load in cerebrospinal fluid and brain. Ann Neurol 1997;42:689-698. 
9. Ellis RJ, Moore DJ, Childers ME, et al. Progression to neuropsychological impairment in human immunodeficiency virus infection predicted by elevated cerebrospinal fluid levels of human immunodeficiency virus RNA. Arch Neurol 2002;59:923-928.

10. Childs EA, Lyles RH, Selnes OA, et al. Plasma viral load and CD4 lymphocytes predict HIV-associated dementia and sensory neuropathy. Neurology 1999;52:607-613.

11. Conant K, Garzino-Demo A, Nath A, et al. Induction of monocyte chemoattractant protein-1 in HIV-1 Tat-stimulated astrocytes and elevation in AIDS dementia. Proc Natl Acad Sci USA 1998;95:3117-121.

12. Cinque P, Vago L, Mengozzi M, et al. Elevated cerebrospinal fluid levels of monocyte chemotactic protein-1 correlate with HIV-1 encephalitis and local viral replication. AIDS 1998;12:1327-1332.

13. Kelder W, McArthur JC, Nance-Sproson T, McClernon D, Griffin DE. Beta-chemokines MCP-1 and RANTES are selectively increased in cerebrospinal fluid of patients with human immunodeficiency virusassociated dementia. Ann Neurol 1998;44:831-835.

14. Conant K, McArthur JC, Griffin DE, Sjulson L, Wahl LM, Irani DN Cerebrospinal fluid levels of MMP-2, 7, and 9 are elevated in association with human immunodeficiency virus dementia. Ann Neurol 1999; 46:391-398.

15. Liuzzi GM MC, Santacroce MP, Fanelli M, D'Agostino C, Vullo V, Riccio $\mathrm{P}$. Increased activity of matrix metalloproteinases in the cerebrospinal fluid of patients with HIV-associated neurological diseases. J Neurovirol 2000;6:156-163.

16. Gallo P, Pagni S, Giometto B, et al. Macrophage-colony stimulating factor (M-CSF) in the cerebrospinal fluid. J Neuroimmunol 1990;29:105-112.

17. Mastroianni CM, Paoletti F, Valenti C, Vullo V, Jirillo E, Delia S Tumour necrosis factor (TNF-alpha) and neurological disorders in HIV infection. J Neurol Neurosurg Psychiatry 1992;55:219-221.

18. Stern Y, McDermott MP, Albert S, et al. Factors associated with incident human immunodeficiency virus-dementia. Arch Neurol 2001:58:473-479.

19. Marra CM, Lockhart D, Zunt JR, Perrin M, Coombs RW, Collier AC Changes in CSF and plasma HIV-1 RNA and cognition after starting potent antiretroviral therapy. Neurology 2003;60:1388-1390.

20. Antinori A, Giancola ML, Grisetti S, et al. Factors influencing virological response to antiretroviral drugs in cerebrospinal fluid of advanced HIV-1-infected patients. AIDS 2002;16:1867-1876.

21. Fahn S, Marsden C, Caine D. Recent developments in Parkinson's disease. Florham Park, NJ: Macmillan Healthcare Information, 1987.

22. Butters N, Grant I, Haxby J, et al. Assessment of AIDS-related cognitive changes: recommendations of the NIMH Workshop on Neuropsychological Assessment Approaches. J Clin Exp Neuropsychol 1990;12:963-978.

23. Rey A. L'examen psychologique dans les cas d'encephalopathie traumatique. Arch Psychol 1941;28:286-340.

24. Wechsler D. Wechsler Adult Intelligence Scale-Revised. New York: Psychological Corp., 1981.

25. Klove H. Clinical neuropsychology. Med Clin North Am 1963;46:16471658 .

26. Benton AL, Hamsher KD. Multilingual Aphasia Examination. Iowa City: University of Iowa, 1976.

27. Flowers KA, Robertson C. The effects of Parkinson's disease on the ability to maintain a mental set. J Neurol Neurosurg Psychiatry 1985; 48:517-529.

28. Richards M, Cote LJ, Stern Y. Executive function in Parkinson's disease: set-shifting or set-maintenance? J Clin Exp Neuropsychol 1993; 15:266-279.

29. Stern Y, Andrews H, Pittman J, et al. Diagnosis of dementia in heterogeneous population. Development of a neuropsychological paradigm-based diagnosis of dementia and quantified correction for the effects of education. Arch Neurol 1992;49:453-460.

30. Nelson HE, O'Connell A. Dementia: the estimation of premorbid intelligence levels using the New Adult Reading Test. Cortex 1978;14:234244 .

31. Miller EN, Satz P, Visscher B. Computerized and conventional neuropsychological assessment of HIV-1-infected homosexual men. Neurology 1991;41:1608-1616.

32. Selnes OA, Jacobson L, Machado AM, et al. Normative data for a brief neuropsychological screening battery. Multicenter AIDS Cohort Study. Percept Mot Skills 1991;73:539-550.

33. Concha M, Selnes OA, McArthur JC, et al. Normative data for a brief neuropsychologic test battery in a cohort of injecting drug users. Int $J$ Addict 1995;30:823-841.

34. Katz S, Ford A, Moschowitz R, Jackson BA, Jaffe MW. Studies of illness on the aged: the index of ADL. JAMA 1963;183:914-919.

35. Lawton MP, Brody EM. Assessment of older people: self-maintaining and Instrumental Activities of Daily Living. Gerontologist 1969;9:179-186.

36. Stewart AL, Ware JE. Measuring function and well-being: The Medical Outcomes Study Approach. Durham, NC: Duke University Press, 1993.

37. Karnofsky DA, Abelman WH, Carver LF. The use of nitrogen mustards in the palliative treatment of carcinoma. Cancer 1948;1:634-656.

38. Beck AT, Beamesderfer A. Assessment of depression: the depression inventory. Mod Probl Pharmacopsychiatry 1974;7:151-169.

39. Beck AT, Ward CH, Mendelson M, Mock J, Erbaugh J. An inventory for measuring depression. Arch Gen Psychiatry 1961;4:561-571.
40. Clinical confirmation of the American Academy of Neurology algorithm for HIV-1-associated cognitive/motor disorder. The Dana Consortium on Therapy for HIV Dementia and Related Cognitive Disorders. Neurology 1996;47:1247-1253.

41. Price RW, Brew BJ. The AIDS dementia complex. J Infect Dis 1988; 158:1079-1083.

42. Marder K, Albert SM, McDermott MP, et al. Inter-rater reliability of a clinical staging of HIV-associated cognitive impairment. Neurology 2003;60:1467-1473.

43. Chiesi A, Vella S, Dally LG, et al. Epidemiology of AIDS dementia complex in Europe. AIDS in Europe Study Group. J Acquir Immune Defic Syndr Hum Retrovirol 1996;11:39-44.

44. Abdulle S, Hagberg L, Svennerholm B, Fuchs D, Gisslen M. Continuing intrathecal immunoactivation despite two years of effective antiretroviral therapy against HIV-1 infection. AIDS 2002;16:2145-2149.

45. Eggers C, Hertogs K, Sturenburg HJ, van Lunzen J, Stellbrink HJ. Delayed central nervous system virus suppression during highly active antiretroviral therapy is associated with HIV encephalopathy, but not with viral drug resistance or poor central nervous system drug penetration. AIDS 2003;17:1897-1906.

46. Staprans S, Marlowe N, Glidden D, et al. Time course of cerebrospinal fluid responses to antiretroviral therapy: evidence for variable compartmentalization of infection. AIDS 1999;13:1051-1061.

47. Brodt HR, Kamps BS, Gute P, Knupp B, Staszewski S, Helm EB Changing incidence of AIDS-defining illnesses in the era of antiretroviral combination therapy. AIDS 1997;11:1731-1738.

48. De Luca A, Ciancio BC, Larussa D, et al. Correlates of independent HIV-1 replication in the CNS and of its control by antiretrovirals. Neurology 2002;59:342-347.

49. Gisslen M, Svennerholm B, Norkrans G, et al. Cerebrospinal fluid and plasma viral load in HIV-1-infected patients with various antiretroviral treatment regimens. Scand J Infect Dis 2000;32:365-369.

50. Aukrust P, Liabakk NB, Muller F, Lien E, Espevik T, Froland SS. Serum levels of tumor necrosis factor-alpha (TNF alpha) and soluble TNF receptors in human immunodeficiency virus type 1 infectioncorrelations to clinical, immunologic, and virologic parameters. J Infect Dis 1994;169:420-424.

51. Aukrust P, Muller F, Lien E, et al. Tumor necrosis factor (TNF) system levels in human immunodeficiency virus-infected patients during highly active antiretroviral therapy: persistent TNF activation is associated with virologic and immunologic treatment failure. J Infect Dis 1999;179:74-82.

52. Zink MC, Coleman GD, Mankowski JL, et al. Increased macrophage chemoattractant protein-1 in cerebrospinal fluid precedes and predicts simian immunodeficiency virus encephalitis. J Infect Dis 2001;184: 1015-1021.

53. McArthur JC, McDermott MP, McClernon D, et al. Attenuation of CNS infection in advanced HIV/AIDS with combination antiretroviral therapy. Arch Neurol 2003 (in press)

54. Gisolf EH, van Praag RM, Jurriaans S, et al. Increasing cerebrospinal fluid chemokine concentrations despite undetectable cerebrospinal fluid HIV RNA in HIV-1-infected patients receiving antiretroviral therapy. J Acquir Immune Defic Syndr 2000;25:426-433.

55. Pulliam L, Gascon R, Stubblebine M, McGuire D, McGrath MS. Unique monocyte subset in patients with AIDS dementia. Lancet 1997;349: 692-695.

56. Gartner S. HIV infection and dementia. Science 2000;287:602-604

57. McArthur J, Hoover D, Bacellar H, et al. Dementia in AIDS patients: incidence and risk factors. Multicenter AIDS Cohort Study. Neurology 1993;43:2245-2252.

58. Brew BJ, Dunbar N, Pemberton L, Kaldor J. Predictive markers of AIDS dementia complex: CD4 cell count and cerebrospinal fluid concentrations of beta 2-microglobulin and neopterin. J Infect Dis 1996;174: $294-298$.

59. Deutsch R, Ellis RJ, McCutchan JA, Marcotte TD, Letendre S, Grant I. AIDS-associated mild neurocognitive impairment is delayed in the era of highly active antiretroviral therapy. AIDS 2001;15:1898-1899.

60. Sacktor NC, Skolasky RL, Lyles RH, Esposito D, Selnes OA, McArthur JC. Improvement in HIV-associated motor slowing after antiretroviral therapy including protease inhibitors. J Neurovirol 2000;6:84-88.

61. Sacktor NC, Lyles RH, Skolasky RL, et al. Combination antiretroviral therapy improves psychomotor speed performance in HIV-seropositive homosexual men. Multicenter AIDS Cohort Study (MACS). Neurology 1999;52:1640-1647.

62. Price RW, Yiannoutsos CT, Clifford DB, et al. Neurological outcomes in late HIV infection: adverse impact of neurological impairment on survival and protective effect of antiviral therapy. AIDS Clinical Trial Group and Neurological AIDS Research Consortium study team. AIDS 1999;13:1677-1685.

63. Tozzi V, Balestra P, Galgani S, et al. Positive and sustained effects of highly active antiretroviral therapy on HIV-1-associated neurocognitive impairment. AIDS 1999;13:1889-1897.

64. Zhang K, McQuibban GA, Silva C, et al. HIV-induced metalloproteinase processing of the chemokine stromal cell derived factor-1 causes neurodegeneration. Nat Neurosci 2003;6:1064-1071. 